\title{
A particularidade histórica da pesquisa no Serviço Social
}

Jussara Ayres Bourguignon

Universidade Estadual de Ponta Grossa (UEPG)

\section{A particularidade histórica da pesquisa no Serviço Social}

Resumo: O objetivo deste estudo ${ }^{1}$ é trazer uma reflexão sobre a particularidade histórica da pesquisa no Serviço Social, bem como sobre os desafios decorrentes desse conjunto especial de circunstâncias que se apresentam no contexto contemporâneo. O estudo percorre e se apóia em três pilares, os quais são trabalhados a partir da particularidade da pesquisa para o Serviço Social; da centralidade ocupada pelos sujeitos que participam das referidas pesquisas e do retorno e do alcance social procedentes desses estudos, para transformações materiais nas condições de existência dos envolvidos, nas ações dos profissionais e nas organizações sociais. O estudo conclui na reafirmação de que a pesquisa é constitutiva e constituinte da prática profissional do Serviço Social, sendo determinada pela sua natureza interventiva e pela sua inserção histórica na divisão sociotécnica do trabalho.

Palavras-chave: pesquisa em Serviço Social, produção de conhecimento, prática profissional.

\section{The Historic Particularity of Social Work Research}

Abstract: The objective of this study is to reflect on the historic particularity of Social Work research and of the challenges related to the special set of circumstances that are presented in the contemporary context. The study is supported by and considers three pillars, which are analyzed from the particularity of Social Work research. They include: the centrality occupied by the subjects that participate in the referred to research; the return and social scope of these studies; and the material transformations in the conditions of those involved, in the actions of the professionals and in social organizations. The study concludes by reaffirming that research is constitutive and constituent of the professional practice of Social Work, being determined by its intervening nature and by its historic insertion in the social technical division of labor.

Key words: Social Work research, production of knowledge, professional practice. 


\section{Introdução}

A observação da trajetória do Serviço Social, como profissão reconhecida e inscrita na divisão sociotécnica do trabalho, permite identificar uma história de avanços e conquistas, no sentido de consolidar uma produção de conhecimento que lhe dá sustentação teórica e metodológica para intervir na realidade social de forma crítica e criativa, e que este processo de intervenção se faz respaldado em projeto ético e político, comprometido com os interesses coletivos dos cidadãos e com a construção de uma sociedade justa.

Há que se considerar que as pesquisas em Serviço Social têm contribuído para avanços significativos em diferentes campos da ação profíssional, no âmbito das políticas públicas, no enfrentamento das expressões da questão social em diferentes momentos históricos, na construção da proposta curricular e definição dos seus fundamentos teóricos e metodológicos, na consolidação do projeto ético-político profissional, entre outros aspectos.

Interessa-nos demarcar que o contexto de nossas inquietações e reflexões refere-se às décadas de 1980 e 1990. Os anos 80 marcam uma etapa de amadurecimento da produção teórica profissional, sendo a Universidade a grande protagonista deste processo. Já os anos 90 representam avanços quanto à consolidação do projeto ético-político da categoria, o que repercutiu nas proposições destinadas à formação profissional e no direcionamento social da mesma; aspectos essenciais para o desenvolvimento crítico, consolidação e reconstrução da própria natureza da atividade.

As décadas de 1980 e 1990 marcam historicamente avanços e conquistas para o Serviço Social nos seus diferentes campos de ação, bem como em seu processo de constituir-se e de consolidar-se como espaço de produção de conhecimento, em seu próprio âmbito e frente às demais áreas de conhecimento, conforme sintetizado a seguir.

\section{Marcos históricos e expressões do Serviço Social}

A partir da década de 1980, institui-se, de modo mais sistemático, o debate acadêmico do Serviço Social, marcando um processo de ruptura com o conservadorismo presente na constituição da profissão. Durante esta década, o processo de rompimento com o conservadorismo gerou no interior da profissão uma cultura que reconhece a pluralidade teóricometodológica, no entanto, fortalece a orientação marxista como direção hegemônica para o projeto éticopolítico profissional. Esta orientação coloca como valor central os princípios de democracia, liberdade, justiça social e dignidade humana, definidos e explicitados no Código de Ética de 1993 (BRASIL, 1997), marco significativo para a profissão nos anos 90 .

A década de 80 marca o reencontro do Serviço Social consigo mesmo, no que se refere à busca de estabelecimento de novas bases para a compreensão do seu passado histórico, das particularidades de sua prática na sociedade marcada por relações de classe, da sua relação com o Estado e com as forças da sociedade civil e de sua posição quanto às demandas sociais, cada vez mais complexas, situandose no âmbito da divisão sociotécnica do trabalho.

Ainda nesta década, o Serviço Social enfrenta questões sobre as políticas sociais, em especial quanto à consolidação de políticas públicas nas áreas da seguridade social (abarcando o tripé saúde, assistência e previdência social) e do trabalho. Estas, entre outras instâncias das políticas públicas, passam a ser pauta do debate da profissão, gerando produções acadêmicas que dão visibilidade às temáticas, bem como à ação profissional desencadeada nestas áreas. Tais preocupações contribuíram para que o Serviço Social enfrentasse, e continue enfrentando junto à sociedade civil organizada, os impasses, desafios e dilemas que a democracia, a cidadania e os direitos sociais colocam à prática social, e neste âmbito em especial, à pratica do profissional do Serviço Social.

A maior parte dos temas de pesquisa dos anos 80, e que prosseguem abordadas nos anos 90, refere-se às políticas públicas na sua interface com o Estado. Exemplo disto é a temática Seguridade Social, a partir de seu marco histórico que é a Constituição Federal de 1988. Recentemente, vêm avançando as investigações sobre a sociedade civil, os processos de gestão e controle das políticas públicas e o papel dos Conselhos de Direitos. Também ganha ênfase o campo de preocupação relativo aos usuários do Serviço Social, muito embora na sua relação com as políticas públicas.

Marcos históricos recentes e relevantes são os dez anos da Lei Orgânica de Assistência Social (PARANÁ, 1994), comemorados em 2003 e os dez anos do Estatuto da Criança e do Adolescente (BRASIL, 2006), em 2000. Eventos que retratam conquistas no campo dos direitos sociais, principalmente em relação à proteção social, destinada aos segmentos vítimas do processo de exclusão social, como famílias, crianças, adolescentes, idosos e portadores de necessidades especiais.

Em 1993 a regulamentação da LOAS garante maioridade jurídica à assistência social, trazendo-a para o campo do direito com responsabilização do Estado, e expressa a recusa da tradição clientelista, assistencialista e tutelar presente, ainda, em suas ações. A assistência social adquire estatuto de política pública e enfrenta, desafios: superar o caldo cultural marcado por essas características que, muitas vezes, norteiam as ações do Estado e das entidades 
sem fins lucrativos, atuantes nesta esfera da política pública; avançar em relação ao processo de avaliação da gestão da política em suas diferentes instâncias; consolidar um processo de controle social, com efetiva participação da sociedade civil. Além disso, propõe-se a assegurar financiamento adequado à complexidade das ações de enfrentamento à pobreza, da garantia dos mínimos sociais, do desenvolvimento de ações de prevenção, de proteção e inclusão social e de repensar as ações destinadas à família de baixa renda, que preconizam o caráter intersetorial e o rompimento com a segmentação da família em suas unidades. A família brasileira, devido às transformações em termos de composição e significados, especialmente a família de baixa renda, reclama por respostas coerentes às suas demandas. $\mathrm{O}$ lugar da família no âmbito das políticas públicas é uma questão que merece aprofundamento e está em debate no contexto da profissão.

Merece destaque o esforço de construção do Sistema Único de Assistência Social (SUAS), viabilizado pela Secretaria Nacional de Assistência Social e pelo Conselho Nacional de Assistência Social em 2004. O SUAS responde às deliberações da IV Conferência Nacional de Assistência Social, realizada em 2003, e materializa pelas diretrizes da LOAS, no entanto, conforme Boschetti (2004, p. 117), seu resultado "[...] como estratégia de resgate da Loas e de fortalecimento do sistema descentralizado e participativo, ainda está por ser avaliado [...]", o que certamente exigirá processo de acompanhamento e investigação por parte dos núcleos de estudos, dos profissionais e dos pesquisadores da área.

Igualmente ganham maior visibilidade as diversas formas de expressão da questão social, havendo um grande esforço teórico-crítico, no sentido de apreendê-las no movimento contraditório da sociedade, possibilitando maior consistência à prática profissional no enfrentamento destas expressões. No movimento das transformações societárias, e de forma inerente no movimento de repensar a profissão, há um processo de construção e afirmação de um projeto ético-político comprometido com a cidadania e renovador da direção social da formação profissional. Não menos relevante, este movimento repercute na elaboração de uma proposta curricular em que a formação profissional direciona-se para o desenvolvimento de uma competência teórico-metodológica de natureza pluralista, orientada pela tradição marxista. Nesta perspectiva, a formação profissional funda-se na interlocução com o conjunto de conhecimentos científicos, acumulados pelas diversas áreas das ciências humanas e sociais, especialmente dialogando com as vertentes clássicas.

A discussão da Reforma Curricular preocupa-se em aprofundar a reflexão sobre a dimensão técnicooperativa do Serviço Social, de forma coerente com a dinâmica societária e capaz de apreender esta dinâmica em sua totalidade e processualidade histórica. Neste contexto, a pesquisa surge como uma preocupação formativa. Trata-se de um desafio a ser enfrentado e proposto pelas novas diretrizes curriculares, ou seja:

[...] garantir uma formação profissional à base da pesquisa e sob a ótica pluralista, considerando que a dimensão investigativa se constitui um princípio e condição de formação e das práticas profissionais e que a postura pluralista supõe relações democráticas construídas na interlocução crítica entre portadores de perspectivas político - ideológicas diferenciadas (CARDOSO, 2000, p. 16).

A pesquisa tem sido privilegiada, em alguns contextos, no âmbito da profissão, estimulando a atitude investigativa na postura e no exercício profissional. Em sua trajetória histórica, a profissão, ao construir e reconstruir um legado teórico, estabelece diálogo crítico com outras áreas do conhecimento, sendo importante interlocutora no campo das reflexões sobre a questão social e seu enfrentamento através da política pública. Neste sentido, destacamos as ações, eventos acadêmicos, discussões e produções dos profissionais do campo sociojurídico, que nos últimos anos vêm ganhando expressão ao promover o debate sobre as particularidades da prática profissional neste campo.

Porém, ao mesmo tempo potencialidade para o Serviço Social, e é neste contexto que se enfrenta o desafio de construir articulações orgânicas, entre a produção de conhecimento e a prática profissional. em que muito já se fez e se conquistou, nas duas últimas décadas do século 20, a pesquisa continua sendo uma exigência que as vicissitudes do mundo contemporâneo colocam à profissão, o que carece de maiores investimentos e uma postura do profissional de permanente crítica e indignação com as manifestações sociais do modelo de desenvolvimento econômico, que sujeita a maioria da população ao processo de exclusão social.

Não podemos negar que a tradição da pesquisa está restrita à Universidade, mais especificamente circunscrita ao nível da pós-graduação. Existe uma 
tendência em aceitar que produzir conhecimento é competência apenas de docentes, de especialistas, e que deve ocorrer no espaço acadêmico.Práticas e representações da pesquisa, restritas ao meio acadêmico favorecem a falta de iniciativas e investimentos na preparação do profissional como pesquisador. Reconhecemos que a própria inserção da profissão na divisão sociotécnica do trabalho impõe limites quanto aos investimentos institucionais, para fomento à pesquisa, quanto ao reconhecimento da sua produção, bem como quanto à incorporação da prática investigativa pelos profissionais. Romper com a dicotomia prática profissional versus pesquisa científica é o desafio que se coloca à profissão. E aqui é importante afirmar que o rompimento será feito através de um processo mediado pelo movimento da própria realidade.

A relação do Serviço Social com a pesquisa surge em função de um processo histórico de amadurecimento intelectual e de ampliação das demandas sociais, o qual vai revelando uma profissão capaz de gestar conhecimentos que lhe acrescentam subsídios teórico-metodológicos, coerentes com sua natureza e com as exigências societárias. Entretanto, é no contexto acadêmico que a pesquisa se revela como potencialidade para o Serviço Social, e é neste contexto que se enfrenta o desafio de construir articulações orgânicas, entre a produção de conhecimento e a prática profissional.

\section{Dimensões da particularidade da pesquisa no Serviço Social}

Pesquisar é exercício sistemático de indagação da realidade observada, buscando conhecimento que ultrapasse nosso entendimento imediato, com um fim determinado e que fundamenta e instrumentaliza o profissional a desenvolver práticas comprometidas com mudanças significativas, no contexto em que se insere e em relação à qualidade de vida do cidadão (GATTI, 2002).

O Serviço Social como profissão sócio-histórica tem em sua natureza a pesquisa como meio de construção de um conhecimento comprometido com as demandas específicas da profissão e com as possibilidades de seu enfrentamento. Ao mesmo tempo em que se coloca como uma possibilidade de objetivação da prática profissional, a pesquisa representa um desafio permanente para os profissionais que pretendem ser críticos e propositivos no atual cenário nacional e em relação ao processo de formação profissional.

E fundamental compreender o processo de produção de conhecimento, como elemento de transformação da realidade social pela mediação do trabalho, reconhecendo o conhecimento como uma das expressões da práxis, como uma das objetivações possíveis do trabalho humano frente aos desafios colocados pela relação entre o homem, a natureza e a sociedade ${ }^{2}$. Neste contexto, a pesquisa ganha significado ontológico, ou seja, existencial e laborativo, pois faz parte da natureza humana perguntar pelo desconhecido para, através das possibilidades de respostas, atender às necessidades do homem em suas dimensões individual e coletiva, produzindo e reproduzindo sua própria existência, não de forma mecânica, mas de forma complexa, processual, contraditória e histórica.

Sustentado nesta perspectiva e reconhecendo a atualidade da problemática da pesquisa, este texto tem como pressuposto orientador que " [...] a pesquisa é constitutiva e constituinte da prática profissional do Serviço Social, sendo determinada pela sua natureza interventiva e pela inserção histórica na divisão sociotécnica do trabalho"(BOURGUIGNON, 2005).É constitutiva e constituinte porque faz parte da natureza da profissão e aparece e se desenvolve socialmente, ao desvendar a complexidade do real e nele buscar as possibilidades de intervenção. Articulada a este pressuposto e na sua interface, a este texto interessa, também, a centralidade que as pesquisas desenvolvidas pelo Serviço Social garantem aos sujeitos que delas são participantes, bem como o alcance social destas pesquisas, considerando a sua repercussão nas organizações sociais, em que trabalha o assistente social, e nas condições de vida dos sujeitos que requisitam sua prática profissional.

\subsection{A particularidade da pesquisa para o Servi- ço Social}

A categoria 'particularidade' vem contribuir para uma aproximação ao processo sócio-histórico em que a pesquisa ganha expressão e força no âmbito do Serviço Social, em especial, considerando as décadas de 1980 e 1990. Para Lukács (1970, p.103-104), a particularidade se constitui de "um campo de mediações", a partir do qual podemos apreender o movimento dialético do universal ao singular: "O movimento do singular ao universal e vice-versa é sempre mediatizado 
pelo particular; é um membro intermediário real, tanto na realidade objetiva quanto no pensamento que a reflete de um modo aproximativamente adequado".

O questionamento sobre a particularidade da pesquisa em Serviço Social estabelece o reconhecimento da necessidade de inserir esta discussão no contexto socioeconômico, político e cultural contemporâneo, buscando apreender as determinações mais gerais e sua repercussão/incidência no âmbito da prática singular desta profissão, principalmente quando enfrenta as demandas sociais e as exigências de seu equacionamento.

A categoria 'particularidade', em sua complexidade e riqueza ontológica, possibilita-nos compreender a pesquisa em sua vinculação orgânica com a prática profissional. Esta vinculação se constrói no movimento histórico da própria profissão e se constitui como possibilidade de avanço teórico-prático, coerente com o projeto ético-político do Serviço Social. Como disse Lukács (1970, p. 66) "O particular, porém, é mais do que um momento da mediação apenas formalmente necessário. Vimos que estão em jogo conexões reais da realidade, da natureza e da sociedade, que recebem na lógica seu mais abstrato reflexo, mas um reflexo que corresponde tendencialmente à realidade."

Não se trata, portanto, de ilustração teórica, mas de apreendermos a pesquisa em sua íntima relação com a prática profissional e no contexto sócio-histórico em que a profissão se constrói, consolida-se e se reconstrói, num movimento em que as contradições e desafios presentes neste contexto instigam a profissão permanentemente à sua superação. Segundo Battini (1991, p. 52),

A união que a particularidade realiza entre uma determinada singularidade e uma determinada universalidade, mediante uma série de determinações mediadoras resgatadas na tensão dos pólos, constantemente em ato, expressa as contradições, fazendo existir uma autêntica e verdadeira aproximação à compreensão adequada da realidade.

O particular, entretanto, não se configura como um simples elo de ligação entre o universal e o singular. Possui um caráter posicional, apresentando-se com relação ao singular como universalidade relativa e ao universal, como singularidade relativa. Mesmo assim, essa relatividade posicional deve ser concebida como um processo que engendra uma base crítica que se obtém no movimento permanente de '...descoberta das reais mediações para cima e para baixo na relação dialética do universal e particular'. ${ }^{3}$ É na particularidade que devemos ver, tanto um princípio de movimento do conhecimento, quanto uma etapa, um momento do caminho dialético.

Como campo de mediações, a particularidade manifesta a possibilidade de compreensão do movi- mento e das relações presentes nos fenômenos. Ao se pensar pesquisa, enquanto particularidade, estamos refletindo sobre os processos e elementos que mobilizam, inspiram e sustentam a atitude investigativa e a prática da pesquisa no âmbito do Serviço Social. Concordamos com Battini (1991, p. 53), ao afirmar que a atitude investigativa é manifestação de um processo que envolve o questionamento permanente dos fatos, buscando sempre novas explicações, superando os limites impostos pela realidade social e pelo conhecimento acumulado pelas ciências. Constituise em "[...] posição viva, ativa e aberta para o emergente, podendo, na prática, serem levantadas questões ou problemáticas que possam vir a se constituir em objetos de pesquisa científica."

A prática da pesquisa no Serviço Social se põe como construção histórica que se processa na medida em que a profissão enfrenta as demandas sociais decorrentes do agravamento da questão social, em suas múltiplas manifestações, tendo como referência a perspectiva teórico-metodológica crítica que sustenta a produção de conhecimento e a intervenção na profissão. Consolida-se no processo de construção e afirmação do projeto ético-político profissional, comprometido com a democracia e justiça social, materializado no Código de Ética de 1993 e no processo de Revisão Curricular, que fundamenta a formação profissional. Também se constitui na medida em que a profissão alcança maturidade intelectual, evidenciada pela sua produção teórica e capacidade de diálogo crítico, com diferentes áreas de conhecimento das ciências sociais e humanas.

É notório o protagonismo dos assistentes sociais nesta construção, que, através das suas organizações representativas - Conselho Federal de Serviço Social (CFESS), Conselho Regional de Serviço Social (CRESS) e Associação Brasileira de Ensino e Pesquisa em Serviço Social (ABEPSS) - e dos espaços de socialização de conhecimentos (congressos, conferências, encontros, seminários, cursos, publicações, entre outros), têm-se mobilizado e se feito presente como sujeito político diante das questões que afetam o exercício profissional e a garantia dos direitos sociais no campo das políticas públicas, bem como têm mantido importante interlocução com os movimentos sociais da sociedade civil, ampliando seu potencial de enfrentamento das crises e transformações do mundo contemporâneo.

$\mathrm{Na}$ trajetória histórica da profissão, a atitude investigativa se faz presente, sendo constitutiva e constituinte. Constitutiva porque a prática profissional está fundamentada na relação dinâmica teoria/ prática, fazendo parte da natureza da profissão buscar compreender criticamente os fenômenos sociais para fundamentar sua intervenção. Constituinte porque, inegavelmente, os avanços observados na esfe- 
ra da produção de conhecimento, da prática profissional no âmbito das políticas públicas e da formação, mobilizam a reconstrução crítica da própria natureza profissional. Neste processo, a profissão sofre determinações estruturais que, contraditoriamente, tanto a desafiam, como, por vezes, lhe criam barreiras, impedindo que, na sua singularidade, muitos profissionais ainda não percebam a vinculação orgânica entre intervenção/investigação.

\subsection{A centralidade dos sujeitos nas pesquisas do Serviço Social}

Há uma lacuna nas produções sobre a pesquisa em Serviço Social, que é justamente a questão da centralidade do sujeito e sua preservação no processo metodológico de investigação do real e consequiente produção de conhecimento profissional. Neste caso, estamos nos referindo ao sujeito demandatário da prática profissional, beneficiário/usuário das políticas públicas, que como cidadão deve ser considerado protagonista de sua própria história e não dado ou fonte de informação. Preocupar-se com o sujeito implica em não perder de vista o contexto sócio-histórico em que se insere e em que se dão as relações entre o profissional assistente social e o cidadão.

A preocupação com o reconhecimento do sujeito-cidadão está presente no projeto ético-político da profissão e necessita ganhar maior relevância, tanto no âmbito da prática profissional em organizações sociais, como no desenvolvimento de pesquisas científicas. A pesquisa deve não só compreender as questões estruturais, mas também a perspectiva de totalidade do processo de reprodução material e espiritual da existência do ser social. Por isso, as diferentes formas de como o sujeito se relaciona com a realidade social não podem passar despercebidas nas pesquisas da área.

O grande desafio para o pesquisador assistente social, que se preocupa com a centralidade do sujeito 'enquanto condição ontológica e não como estratégia metodológica de pesquisa', é possibilitar através da pesquisa maior visibilidade ao sujeito, à sua experiência e ao seu conhecimento, cuja natureza, se desvendada, poderá permitir desenvolver práticas cada vez mais comprometidas ética e politicamente com a realidade, buscando no coletivo e na troca de saberes alternativas de superação das condições de privação e exclusão social.

Vinculada à prática profissional e com o desafio de fundamentá-la, reanimá-la e renová-la, a pesquisa em Serviço Social trabalha com objetos plenos de significados atribuídos pelos diversos sujeitos que se constituem participantes da prática profissional do assistente social. Os objetos de atenção profissional, no âmbito da pesquisa e no âmbito da intervenção, trazem à tona a experiência e o co- nhecimento destes sujeitos, os quais precisam ser compartilhados, compreendidos e traduzidos à luz de um diálogo crítico com o corpo de conhecimentos já acumulados pelo Serviço Social.

A preocupação com a centralidade que o sujeito ocupa nas pesquisas do Serviço Social não é ocasional, revela que a profissão tem suas ações e preocupações pautadas nas demandas dos usuários, que se expressam através das histórias de vida que trazem às organizações sociais, nas relações que movimentam no seio da família, do trabalho e da sociedade, nas raízes e expressões culturais que demonstram, nas carências socioeconômicas e políticas que exigem posicionamento do assistente social.

Freire (1985, p. 40), a exemplo de suas contribuições às práticas educativas, lembra-nos que:

Um dos inúmeros aspectos positivos de um trabalho como este é, sem dúvida, fundamentalmente, o reconhecimento do direito que o povo tem de ser sujeito da pesquisa que procura conhecê-lo melhor. E não objeto da pesquisa que os especialistas fazem em torno dele. Nesta segunda hipótese, os especialistas falam sobre ele; quando muito, falam a ele, mas não com ele, pois só o escutam enquanto ele responde às perguntas que lhe fazem.

A pesquisa para o Serviço Social deve gerar um conhecimento que reconheça os usuários dos serviços públicos como sujeitos políticos que são, capazes, também, de conhecer e intervir em sua própria realidade com autonomia, desvencilhando-se das estratégias de assistencialismo, clientelismo e subalternidade, tão presentes nas ações governamentais e políticas públicas. As pesquisas têm como possibilidade latente a valorização do povo, da riqueza de suas histórias, de suas experiências coletivas, mobilizadoras de novas formas de sociabilidade. Apreender estes elementos contribuirá para o desenvolvimento de uma prática capaz de possibilitar aos usuários e destinatários das políticas públicas e dos serviços sociais a experiência de "Assumir-se como ser social e histórico [...]", ou seja, assumir-se "[...] como ser pensante, comunicante, transformador, criador, realizador de sonhos, capaz de ter raiva porque capaz de amar. Assumir-se como sujeito porque capaz de reconhecer-se como objeto" (FREIRE, 1996, p. 41).

Estamos nos referindo a um sujeito que tem em sua natureza uma dimensão coletiva, pois em sua singularidade e relações particulares expressa vinculações de classe. $\mathrm{O}$ que não pode ocorrer, e este é um cuidado metodológico que precisamos desenvolver, é subtrairmos, no processo da pesquisa, a condição de sujeito deste cidadão e enfatizarmos a sua condição de objeto.

A aproximação ao sujeito que participa de nossas pesquisas se faz através da busca da compreensão 
da sua experiência, do conhecimento gerado a partir desta experiência e da sua vivência cotidiana que, tomados em relação ao objeto de estudo, compõem um dos elementos a serem apreendidos na sua relação com as múltiplas determinações de natureza econômica, social, política e cultural.

Para tanto, construímos uma metodologia de investigação que busca estabelecer um tipo de relação com estes sujeitos, a qual pode apresentar diferentes facetas teóricas - fundamentadas pela teoria social que nos alimenta -, naturalmente com a orientação dos objetivos de investigação e pela natureza do objeto de estudo. Portanto, a relação com o sujeito eleito para participar de nossa pesquisa não é ocasional, ingênua, mas definida pelo que se pretende elaborar cientificamente.

Em nosso trabalho, consideramos que a relação com o sujeito se faz através da pesquisa de natureza quantitativa e/ou qualitativa. Não deve ser mérito apenas das pesquisas qualitativas a busca do compreender o sujeito, em uma perspectiva crítica, pois não podemos descartar que o sujeito também se revela através dos dados quantitativos, estes trazem à tona expressões concretas de sua realidade, quando trabalham condições de vida, renda, ocupação. O diferencial está na forma como tratamos estes dados, buscando revelar o quê e o para quê, e por que enfatizamos o quantitativo. São as determinações objetivas, expressas através da pesquisa, que podem fundamentar análises sobre a riqueza da realidade, avaliar projetos e programas sociais e redirecionar ações que garantam a dignidade deste sujeito e os seus direitos sociais, civis e políticos. Precisamos evidenciar que os dados quantitativos não expressam apenas o desenvolvimento econômico de um país, mas como este desenvolvimento incide sobre as condições de vida do cidadão.

Assim, a relação que o Serviço Social deve estabelecer com o conhecimento do sujeito participante de sua investigação/intervenção deve sustentar-se no diálogo crítico, capaz de gerar conhecimentos novos e propiciar a elevação do nível de consciência deste sujeito. A sua experiência e conhecimento alicerçam-se em dinâmicas concretas da realidade, as quais precisam ser transformadas através de ações políticas - ações que sejam, também capazes de resgatar a condição de sujeito de direitos e capazes de romper com as tramas que determinam a condição de subalternidade.

O Serviço Social tem uma rica experiência e um conhecimento acumulado sobre as formas de apro- ximação ao sujeito, além de ser academicamente preparado para isso. A questão que se coloca hoje é que os procedimentos metodológicos de pesquisa preservem a centralidade do sujeito, bem como que o assistente social trabalhe com o conjunto das informações colhidas na realidade, de forma a potencializar em sua intervenção as alternativas que garantam a consolidação dos direitos fundamentais do cidadão.

2.3 O retorno e alcance social das pesquisas em Serviço Social

Orientado pelo compromisso ético-político, o conhecimento construído pelos profissionais precisa ganhar força social e romper com os muros da academia e do próprio Serviço Social, para ser capaz de, através de uma prática crítica e propositiva, interferir nas condições de vida do cidadão. A preocupação com o retorno e alcance social de nossas produções refere-se a uma intenção de fazer o caminho de volta, isto é, retornar à realidade que sustentou a produção de conhecimento e mobilizar ações que transformem esta realidade, seus sujeitos e a própria profissão, alargando seus horizontes e potencializando seus objetivos, suas competências e habilidades profissionais.

Através do conhecimento produzido, é preciso refletir sobre os impactos gerados na realidade social, em que o Serviço Social intervém. E o impacto, no contexto da pesquisa, refere-se às dimensões das transformações e mudanças operadas na profissão, nas condições materiais de existência dos sujeitos/ usuários, nas ações dos profissionais de Serviço Social, nas organizações em que o profissional atua, tendo como mediação o acúmulo de conhecimentos produzidos pela profissão.

Evidenciamos uma dimensão essencialmente política neste aspecto, no sentido de que o conhecimento produzido deve ter uma direção estratégica para uma intervenção profissional, comprometida com processos concretos que garantam materialidade ao seu projeto ético-político.

\section{Considerações finais}

Observamos que o Serviço Social, em sua trajetória histórica, avançou quanto ao acúmulo de conhecimentos sobre o seu objeto de intervenção e sobre a 
natureza da própria profissão. Deixou de ser consumidor do saber produzido por outras áreas de conhecimento das ciências sociais e humanas e passou a ser protagonista de um processo que exige o acompanhamento sistemático e crítico das transformações societárias, que concretamente rebatem no exercício profissional cotidiano. No entanto, precisamos enfatizar alguns elementos, de ordem teórica e prática, necessários à reflexão sobre pesquisa e Serviço Social:

- O conhecimento, resultado do processo de investigação permanente da realidade, deve ter como referência os seus frutos, materializados na prática social humana e em alterações que geram nas condições de vida dos seres humanos, nos seus comportamentos, nas suas atitudes e relações que estabelecem entre si e com a natureza e nas determinações sociais que impedem processos de rompimento com as condições de subalternidade em que se encontram.

- Os objetos de atenção de profissionais/pesquisadores são reconstruções teóricas que se processam vinculados aos objetivos do profissional, à sua experiência pessoal e social, e retratam o nível de engajamento ao seu tempo histórico e ao acúmulo de conhecimentos produzidos socialmente.

- O campo empírico das inquietações profissionais e estimulador da atitude investigativa é a prática profissional. A prática profissional, problematizada, constitui-se em fonte de reflexão e construção de conhecimentos sobre seu objeto de intervenção e suas expressões particulares no contexto socioocupacional, onde o profissional está inserido. Também, é fonte de questionamento da própria prática buscando alternativas de repensá-la e redefinila, conforme as exigências contemporâneas para o seu exercício.

- As articulações entre o conhecimento produzido pelo conjunto da categoria e as demandas profissionais são feitas através de mediações. A intervenção, através de suas intenções, seus projetos e ações cotidianas, estabelece as mediações entre os conhecimentos e as demandas sociais. Desta forma, estas mediações são apreendidas no real e reconstruídas teoricamente, na medida em que o profissional passa da intenção à intervenção, apoiando-se em pesquisa sistemática e crítica dos fenômenos sociais que define estratégias, meios e recursos necessários para o alcance de seus fins.

- A relevância social de uma pesquisa está na sua capacidade de apreender a realidade e de servir de referência para os profissionais da categoria e de outras áreas de conhecimento, sendo assim alimentadora de práticas profissionais.
Consolidar os avanços já conquistados pela profissão em relação à produção de conhecimento requer que o conhecimento produzido extrapole os muros da academia. E o caminho para isso está na própria prática profissional, e nas necessidades de dar ao seu projeto ético-político materialidade sócio-histórica. $\mathrm{Ou}$ seja, precisamos ter uma política de formação que articule graduação, pós-graduação e processos de capacitação e atualização permanentes. Neste conjunto, o eixo de sustentação deve assentar-se nas demandas e nos impasses vivenciados pelos profissionais no contexto do exercício da profissão, considerando as determinações sociais, econômicas, políticas e culturais que expressam a realidade contemporânea e o projeto ético-político profissional.

No processo histórico, em que a produção de conhecimento se materializa via pesquisa no Serviço Social, alguns elementos podem se colocar como mediações possíveis ao exercício da pesquisa, constituindo carizes da sua particularidade. Destes destacamos: a necessária vinculação orgânica com a prática profissional; a garantia de centralidade ao sujeito participante, como condição ontológica a ser recuperada pelas pesquisas; e o compromisso com o retorno e alcance social das mesmas.

Em se tratando da particularidade histórica da pesquisa em Serviço Social, consolidá-la como constitutiva e constituinte da prática profissional é tarefa que não se cumpre individualmente, pelo contrário, é desafio coletivo que deve ser enfrentado pelo conjunto da categoria em todas as instâncias de sua intervenção e no espaço da formação profissional.

\section{Referências}

BATTINI, O. O estado das artes no Serviço Social: estudo sobre a construção do conhecimento na prática profissional do Assistente Social. Tese (Doutorado em Serviço Social) - Pontifícia Universidade Católica de São Paulo, São Paulo, 1991.

BOSCHETTI, I. Seguridade social e projeto ético-político do Serviço Social: que direitos para qual cidadania? Revista Serviço Social \& Sociedade, São Paulo: Cortez, n. 79, p. 108-132, 2004.

BOURGUIGNON, J. A. A particularidade histórica da pesquisa no Serviço Social. Tese (Doutorado em Serviço Social) - Pontifícia Universidade Católica de São Paulo, São Paulo, 2005.

BRASIL. Presidência da República. Estatuto da Criança e do Adolescente. Lei n. 8.069, de 13 de julho de 1990. Dispõe sobre o Estatuto da Criança e do Adolescente e dá outras providências. Disponível em $\leq$ http://www.planalto.gov.br/ ccivil_03/LEIS/L8069.htm>. Acesso em: nov. 2006. 
Conselho Federal de Serviço Social. Código de Ética do Assistente Social. Lei 662/93 da regulamentação da profissão. Brasília: CFESS, 1997.

CARDOSO, F. G. As novas diretrizes curriculares para a formação profissional do Assistente Social: principais polêmicas e desafios. Revista Temporalis, Brasília: ABEPSS, v. 1, n. 2, p. 7-17, jul/dez. 2000.

FERNANDES, F. Sociologia numa era de revolução social. Rio de Janeiro: Zahar, 1976.

FREIRE, P. A importância do ato de ler: em três artigos que se complementam. São Paulo: Autores Associados: Cortez, 1985. (Coleção Polêmicas do Nosso Tempo).

Pedagogia da autonomia: saberes necessários à prática educativa. São Paulo: Paz e Terra, 1996. (Coleção Leitura).

GATTI, B. A. A construção da pesquisa em educação no Brasil. Brasília: Plano Editora, 2002. (Série Pesquisa em Educação, v. 1).

IANNI, O. Dialética e capitalismo. Petrópolis: Vozes, 1985.

KOSIK, K. Dialética do concreto. Rio de Janeiro: Paz e Terra, 1976.

LEFEBVRE, H. Sociologia de Marx. Rio de Janeiro: Forense, 1968.

Lógica formal - Lógica dialética. Tradução de Carlos Nelson Coutinho. Rio de Janeiro: Editora Civilização Brasileira, 1991.

LUKÁCS, G. Introdução a uma estética marxista. Sobre a particularidade como categoria da estética. Tradução de Carlos Nelson Coutinho e Leandro Konder. Rio de Janeiro: Editora Civilização Brasileira, 1970

MARX, K. Contribuição à crítica da economia política. 2. ed. São Paulo: Martins Fontes, 1983.

O capital: crítica da economia política. 12. ed. Rio de Janeiro: Bertrand Brasil, 1988. Livro Primeiro, v. 2.

Manuscritos econômico-filosóficos e outros textos escolhidos. São Paulo: Nova Cultural, 1991

MARX, K.; ENGELS, F. A ideologia alemã. São Paulo: Martins Fontes, 1989.

PARANÁ, Secretaria de Estado do Trabalho e da Ação Social. LOAS - Lei Orgânica da Assistência Social. Curitiba, out. 1994. (Textos de Apoio).
PINTO, À. V. Ciência e existência: problemas filosóficos da pesquisa científica. Rio de Janeiro: Paz e Terra, 1979

VAZQUEZ, A. S. Filosofia da praxis. Rio de Janeiro: Paz e Terra, 1977.

\section{Notas}

1 Este artigo utiliza como base as pesquisas da minha tese de doutorado também intitulada A particularidade histórica da pesquisa no Serviço Social, orientada pela Profa. Dra. Maria Lúcia Martinelli. Adefesa da tese foi em 2005 junto ao Programa de Estudos Pós-Graduados em Serviço Social da PUC-SãoPaulo.

2 Buscamos trilhar um caminho de reflexão sobre o conhecimento humano a partir das obras de Marx e Engels (1989);Marx(1983, 1988, 1991); Pinto(1979); Vázquez(1977); Kosik (1976); Lefebvre (1968, 1991); Ianni $(1984,1985)$ e Fernandes (1976).

3 Citação entre aspas utilizada por Battini (1991) para palavras deLukács (1978).

Jussara Ayres Bourguignon

Doutora em Serviço Social pela PUCSP

Professora adjunta da Universidade Estadual de Ponta Grossa (UEPG) no Departamento de Serviço Social e no Programa de Pós-Graduação em Ciências Sociais Aplicadas

Setor de Ciências Sociais e Aplicadas

Praça Santos Andrade, s/n - Centro

Ponta Grossa - Paraná

CEP: 84010-330 